\title{
Sustainable Communication: Cross-Cultural Management of Higher Education Staff in East Coast of Peninsular Malaysia
}

\author{
Isma Rosila Ismail ${ }^{1, *}$, Che Hasniza Che $\mathrm{Noh}^{2}$, Zaleha Mohamad ${ }^{3}$ \\ ${ }^{I}$ Centre for Foundation \& Continuing Education, Institute of Tropical Biodiversity \& Sustainable Development, \\ Insitute of Marine Biotechnology, Malaysia. \\ ${ }^{2}$ Centre for Foundation \& Continuing Education, Malaysia \\ ${ }^{3}$ Faculty of Business, Economics \& Social Development, Institute of Tropical Biodiversity \& Sustainable Development, \\ Insitute of Marine Biotechnology, Malaysia \\ Corresponding author e-mail address: ismarosila@umt.edu.my
}

\begin{abstract}
This study investigates the ethnic and cultural backgrounds of the University Malaysia Terengganu (UMT) personnel to determine the elements of uncertainty avoidance among the staff. As such, the study examines the respondents' expectations of rules, changes, and creativity in uncertainty avoidance. This study also investigates the differences between respondents' behaviour in High Uncertainty Avoidance (HUA) or Low Uncertainty Avoidance (LUA) and the extent to which these differences affect communication. Furthermore, this study employed mixed (qualitative and quantitative) methods as a research design, with ethnography as a research approach. The study data were analysed using the Statistical Package for Social Science (SPSS Version 20) and thematic analysis for an in-depth exploration of the respondents. The result of the study showed that, regardless of ethnicity, common HUA values were shared in the observation of rules and regulations, which reflected the consensual agreement on the importance of observing rules. Concerning changes and adaptation, all the three ethnic groups indicated LUA, with only a small number indicating HUA in this matter. The Malay personnel indicated an especially high LUA, as the future was believed to be too intricate, ambiguous, unpredictable, and hostile for efficient planning. Regarding workplace creativity, all three ethnic groups indicated LUA, with only a small number indicating HUA in this matter. Nevertheless, it is made aware in this study that the results are not representative of the three ethnic populations in Malaysia.
\end{abstract}

Keywords: intercultural communication, ethnic diversity, sustainable communication, cross-cultural, East Coast Malaysia

\section{Introduction}

The diversity in Malaysia is evident from the three main ethnic and religious groups: Muslim Malays, Chinese Buddhists, and Indian Hindus. These ethnic and religious groups are reflected in the staff composition at UMT, a university in East Coast Malaysia. This university was selected based on the possibilities for potential intercultural communication problems to surface among the multiracial staff 
population. Thus, the objective of this study was to ascertain the degree to which the elements of uncertainty avoidance, such as the values in observing rules and regulations, accepting changes and adaptation, and creativity at the workplace could generate problems and conflicts, subsequently affecting UMT's productivity. The paper addressed this hypothesis by first defining culture in the Malaysian context, such as socio-cultural, linguistic, and educational nuances. Additionally, the paper outlined the method, findings, discussions, and conclusion to contextualise the study.

\section{Background}

As a multicultural country consisting of Malays, Chinese, Indians, people of other ethnicities, and indigenous people, Malaysia consists of diverse values, knowledge, and experiences. As such, each ethnic group possessed unique cultural values. Intercultural communication did not only occur when locals interacted with international residents, but this form of communication also occurred when locals interacted with one another. In other words, intercultural communication did not only refer to interactions between locals and foreigners but included individuals from the same culture (Sitaram, 1980). For example, when Malaysian Chinese and Malays interacted, this could be considered intercultural by nature in the Malaysian setting. Similarly, the interaction between Malaysian Indians and Malaysian Chinese could also be considered as intercultural communication.

Intercultural communication is vital, specifically in the Malaysian context, due to the composition of various ethnic cultures and cultural, religious, and ethnic beliefs. The issues concerning religious beliefs and ethnic tensions are currently being propagated by some local politicians that may disrupt ethnic collaboration (Fuller, 2006; Mydans, 2010). Besides, Malaysia comprised of a diverse population that has long been trying to maintain effective ethnic relationships. If the uniqueness of this composition is taken for granted, many talented non-Malays may migrate to other countries.

Ironically, ethnic groups exhibited harmonious collaboration in terms of festival celebrations and culinary practices. The culinary practices in Malaysia were distinct and derived from the multi-ethnic population of Malays, Indians, Chinese, Nyonyas, Eurasians, and the indigenous people of Borneo. On a global scale, local food items were collectively known as Malaysian food, without distinctions based on ethnic origins. However, the cohesion in Malaysian ethnicity is not as simple or effective as the fusion in food, as each ethnic group has distinct ethnic identities which are instilled with pride and generates a feeling of togetherness. The ethnic groups in this study were analysed based on the concept of 'group' which functioned as "a seemingly unproblematic, taken for granted concept" (Brubaker, 2002). Nonetheless, Brubaker (2002) enlightened that a group or groupism went beyond ethnicity, race, and nationalism.

The blending of the Malaysian ethnicities, however, matched Brubaker's (2002) clarification in which ethnicity would relate to ethnic conflict and define the ethnic group. The complexity of multiculturalism in Malaysia was also explained, as the blending of different cultures proved to be challenging. Also, the full potential of other cultures was not acknowledged and went unnoticed, as any oppositions or assertions made by these cultures were ignored or discouraged due to the dominance of the Malay culture. However, this study did not focus on discussions in ethnicity issues, thus suggesting a separate discussion.

The study investigated the issues prevalent in intercultural communication among the three main ethnic groups in Malaysian universities. The Malaysian higher education encompassed multi-ethnic groups in both student enrolments and staff composition and offered a unique opportunity to analyse the existing intercultural communication issues between the different cultures at the workplace. Thus, higher educational institutions were crucial in promoting diversity and multiculturalism in student bodies and a 
global working environment with a diverse workforce (Pandian, 2008). Therefore, this study intended to identify the communication issues among the multi-ethnic staff in a Malaysian university.

This study focused on East Coast Malaysia, specifically in the state of Terengganu, a multicultural state with ethnic Malays as the dominant group (Terengganu history, 2013). The people of Terengganu used the standard Malay language in formal and government affairs. However, the Terengganese Malay dialect was preferred for daily conversations and business affairs and was even used sometimes by the government staff when dealing with locals or non-locals. As such, the Terengganese Malay dialect was distinct from standard Malay and other state dialects. When non-locals from different ethnic groups, or individuals from the same ethnic group but different states encountered the locals, the possibility of intercultural communication problems was highlighted.

Terengganu has a population of 1,015,776 residents as of 2010 (Terengganu history, 2013). As of 2006, Malays made up $94.7 \%$ of the population, with the Chinese at $2.6 \%$, the Indians at about $0.2 \%$, and other ethnic groups comprising the remaining 2.4\%. Based on the 2010 Census, the population of Terengganu consisted of $96.9 \%$ Muslims, $2.5 \%$ Buddhists, $0.2 \%$ Hindus, $0.2 \%$ Christians, and $0.2 \%$ followers of other religions and non-religious residents. The Malay people of Terengganu largely consisted of Muslims and since this state is Malay-dominant, a significant number of Malays and Muslims was identified compared to other ethnic groups.

The education system could be divided into three eras: the pre-independence, independence, and postindependence eras, which incorporated Malay-medium and religious-based schools. In the preindependence era, the Malayan (currently Malaysian) educational system was based on pondok (literally hut) styles, which were believed to align with the spread of Islam in the 14th century (Othman and Mohamad, 2011).

Furthermore, Arabian and Indian missionaries were the agents who spread Islam and established the non-formal pondok education in almost all the states except Johore and the Straits Settlements (Hamid, 2010; Othman and Mohamad, 2011). Hence, the pondok system promoted free non-formal education and the development of operational skills, such as agricultural and vocational skills funded by the local community. In general, pondok schools, also known as madrasah, were the original forms of schooling available across Malaya (currently Malaysia) (Hamid, 2010; Shamsul and Aziz, 2011). This schooling system also influenced the initial educational system in Terengganu (Majid et al., 2012; Othman and Mohamad, 2011). For example, the locals attended the madrasah or pondok in districts and were taught by the imam or ulama (Othman and Mohamad, 2011; Talib, 1984).

Islamic education was first taught informally to the public and included revealed sciences (teaching the Holy Quran), good behavior, morals, good deeds of worship, Islamic knowledge, and spirituality (Majid et al., 2012). Additionally, the memorization of Al-Quran, the learning of the Qur'an and Sunnah (the prophetic tradition), theology, jurisprudence, the history of Islam including the Prophet Muhammad's biography, and the fundamentals of arithmetic and logic (Othman and Mohamad, 2011) were covered. As such, these religious schools aimed to produce virtuous Muslims adhering to the religious commandments that are significant to the Muslim society, in line with the study conducted by Asma and Lim (2001), whereby religion was one of the significant elements at the Malaysian workplace.

Moreover, mosques, prayer rooms, religious schools, or madrasah were amongst the places where students learned the Islamic sciences. In Terengganu itself, it was noted that in 1838, every village surrounding the royal town of Kuala Terengganu owned a madrasah (religious school) (Talib, 1984). The Islamic education was gradually systematised to compete with the secular schools offered under the British colonization. The first systematic Islamic school was introduced in 1908, during the opening of the Iqbal School in Singapore, and was later introduced to Penang, Muar, Kota Bahru, Terengganu, and 
Alor Setar (Majid et al., 2012). The first madrasah in Terengganu was Madrasah al-'Arabiah which was established in 1925 and used Malay, Arabic, and English as mediums of instruction (Mardman, 2011).

The current national schools practiced formal education that was founded during the British colonial era. At the time, English schools were set up for the locals, and the Malay vernacular schools were established in 1856 (Majid et al., 2012). Malaysian secular schools were introduced by the British colonials with prolific establishments in the Straits Settlements of Penang, Melaka, and Singapore (Othman and Mohamad, 2011). After independence, these vernacular schools were widely accepted by the Malaysian population and became the medium of reformation, specifically with Malaysia's emergence as a multicultural and independent country (Othman and Mohamad, 2011). The school system was then revised and incorporated religion into religious-based schools, with Islamic knowledge offered at most of the national and vernacular schools (Othman and Mohamad, 2011). These schooling systems were also introduced in Terengganu. To date, Terengganu provides religious-based, national, and vernacular schools.

The state of Terengganu is home to two main universities, which are the UMT and University Sultan Zainal Abidin (Unisza, previously known as University Darul Iman). Other university branches based in different states were also located in Terengganu, such as University Technology Mara (UiTM) in Shah Alam, Selangor, and private educational institutions. Specifically, UMT is in Mengabang Telipot, Kuala Terengganu, and is the 14th Malaysian public university located in the East Coast of the Peninsular.

Also, UMT which was previously known as KUSTEM (College of Science and Technology Malaysia) was renamed on the 1st February 2007 and comprised of multi-ethnic staff groups. These ethnic and religious groups were reflected in UMT's staff composition, From the 1,360 administrative staffs, 1,285 staff were ethnic Malays, 50 were ethnic Chinese, 13 were ethnic Indians, and 12 belonged to other ethnic groups. Approximately $94 \%$ of the UMT were Malays, with $4 \%$ of ethnic Chinese, $1 \%$ of ethnic Indians, and the remaining $1 \%$ of other ethnic groups, such as Thais and international staff.

The UMT was selected as a place of study due to the unique composition of ethnic minorities. The majority of UMT personnel were local Malays (Terengganu born) compared to non-local Malays (nonTerengganu born) and other ethnic minorities. As such, this university was chosen based on the representativeness of the Malaysian ethnic composition. Given the uneven ethnic mix, the emergence of potential intercultural communication problems was predicted between the local and non-local Malay staff and other ethnic groups, with the dominance of the Malay culture. Hence, the ethnic and religious differences led to communication breakdowns among the administrative staff, which could simultaneously affect UMT's productivity and students' varsity experiences. Besides, UMT's work environment differed from other universities, as the institution is situated in the northern region with little Western influence during the era of colonisation.

\section{Methodology}

\subsection{Sampling Technique}

This study employed mixed methods as a research design, with ethnography as the research approach. The study methods included both quantitative and qualitative data collection, such as online surveys and semi-structured interviews. A survey was used to identify the respondents' basic understanding, while interviews were used to reflect the respondents' real-life experiences. The study method began by explaining the setting and presenting the survey and interview stages. Respondents were then selected using purposive sampling to complete the survey. A total of 20 respondents were shortlisted for interviews (and e-interviews) to investigate personal experiences concerning intercultural communication in UMT. 


\subsubsection{Sample}

A total of 150 survey respondents were originally invited to participate from April 2011 to August 2011. Although the deadline was extended several times, only $93(62 \%)$ responses were received for the survey, with only 88 (59\%) valid respondents who completed the survey, indicating a good return rate. As for the interviews and e-interviews, 21 out of the 27 targeted respondents completed the interview phase of this study. Also, 14 of the respondents were interviewed in person, and seven of the respondents were e-interviewed.

\subsubsection{Rationale for Sample Choice}

The study focused on the three ethnic groups, namely, Malays (including locals and non-locals), Chinese, and Indians in UMT, as these three ethnic groups reflected the major groups in this university. Also, the respondents were chosen based on several characteristics, such as ethnicity and religion, which justified the purposive sampling technique. As such, the study focused on four organizational levels: the upper, middle, support levels, and the academic staff.

The concept of ethnic groups is significant for this study as:

"Within the three ethnic groups, there is an ease of movement (that suggests) this ethnic paradigm is subject to constant manipulation by ordinary people. It would seem then that the majority of Malaysian recognizes that the tri-ethnic scheme is an abstraction subject to change they can effect in small but radical ways (Fontaine and Richardson, 2003)."

Therefore, this study of 'Malaysians' was undertaken by investigating each ethnic group, as opposed to a single group recommended in intercultural research (Fontaine and Richardson, 2003).

\subsection{Methods}

This study was framed under the Hofstede cultural values theory, verbal communication theory (Hall, 1959 and 1966; Knapp and Hall, 2006), and cross-cultural communication theory (Hofstede and Bond, 1984, Hofstede, 1991, 2001, 2010, 2012, Jackson, 2020, Panocova, 2020). Based on these theoretical frameworks, the study explored the respondent's perspectives and experiences. The study data were sequentially analysed using both SPSS and thematic analysis to deeply explore respondents' experiences.

\section{Results and Discussion}

\subsection{Demographic Profile: Survey Respondents}

One hundred and fifty survey respondents who were originally invited to participate, starting from April 2011 until the dateline, and even though the dateline had been extended for a few times (until August 2011) there were only 93 (62\%) responses to the survey with only 88 (59\%) valid respondents completing the survey, which is a good return rate.

In this study, $60 \%$ of the UMT staff were between the age range of 26 and 35 years, followed by $24 \%$ between the age range of 36 and 45 years, $9 \%$ between the ages of 46 and 55 years, $4 \%$ less than or at $(<=) 25$ years, and $4 \%$ less than or at $(<=) 56$ years. This was consistent with the respondents' age in the study, with the majority between the age ranges of 26 to 35 years employed in UMT for one to five years 
onwards. Additionally, $51.1 \%$ of the respondents were female, and $48.9 \%$ were male. The respondents were divided into three levels of organisation: upper-level, middle-level, and support level.

As most of the respondents comprised of ethnic Malay Muslims, the three organizational levels were dominated by this ethnic group as the study was conducted in East Coast Peninsular Malaysia, where the states in this part of the country were predominantly populated with Malays. However, neither the ethnic Chinese nor the Indians worked at the support level, as most of the individuals were employed at the middle-level. In terms of educational level, all the respondents were qualified with a bachelor's degree, Master's Degree, or Doctoral Degree, including the support level staff. Most of the UMT staff consisted of local Malays (Terengganu born), non-local Malays (non-Terengganu born from various states excluding Terengganu), and other ethnic minorities (including non-Terengganu born Chinese and Indians from various states excluding Terengganu) (See Table 1).

Table 1. Demographic Profile Survey Respondents

\begin{tabular}{|c|c|c|c|c|c|c|c|c|c|}
\hline & & & & Ethr & icity & & & & \\
\hline & & & alay & & ninese & & ndian & & Total \\
\hline & & Frequency & Percentage & & & & & & \\
\hline & & (n) & $(\%)$ & (n) & $(\%)$ & (n) & $(\%)$ & (n) & $(\%)$ \\
\hline Age & $20-25$ years & 1 & 1.3 & 0 & .0 & 0 & .0 & 1 & 1.1 \\
\hline & $26-30$ years & 14 & 18.4 & 3 & 37.5 & 1 & 25.0 & 18 & 20.5 \\
\hline & $31-35$ years & 21 & 27.6 & 2 & 25.0 & 3 & 75.0 & 26 & 29.5 \\
\hline & $36-40$ years & 13 & 17.1 & 2 & 25.0 & 0 & .0 & 15 & 17.0 \\
\hline & $41-45$ years & 14 & 18.4 & 0 & .0 & 0 & .0 & 14 & 15.9 \\
\hline & $46-50$ years & 7 & 9.2 & 0 & .0 & 0 & .0 & 7 & 8.0 \\
\hline & $51-55$ years & 4 & 5.3 & 1 & 12.5 & 0 & .0 & 5 & 5.7 \\
\hline & $56-60$ years & 2 & 2.6 & 0 & .0 & 0 & .0 & 2 & 2.3 \\
\hline & $61-70$ years & 0 & .0 & 0 & .0 & 0 & .0 & 0 & .0 \\
\hline & Total & 76 & 100.0 & 8 & 100.0 & 4 & 100.0 & 88 & 100.0 \\
\hline Gender & Female & 43 & 56.6 & 2 & 25.0 & 0 & .0 & 45 & 51.1 \\
\hline & Male & 33 & 43.4 & 6 & 75.0 & 4 & 100.0 & 43 & 48.9 \\
\hline & Total & 76 & 100.0 & 8 & 100.0 & 4 & 100.0 & 88 & 100.0 \\
\hline Educational & Secondary School (SRP/PMR/SPM) & 8 & 10.5 & 0 & .0 & 0 & .0 & 8 & 9.1 \\
\hline level & Post-Secondary (STPM) & 0 & .0 & 0 & .0 & 0 & .0 & 0 & .0 \\
\hline & $\begin{array}{l}\text { College/Higher education } \\
\text { (Certificate/Diploma) }\end{array}$ & 17 & 22.4 & 0 & .0 & 0 & .0 & 17 & 19.3 \\
\hline & $\begin{array}{l}\text { Higher Education } \\
\text { (PhD/Master/Bachelor) }\end{array}$ & 51 & 67.1 & 8 & 100.0 & 4 & 100.0 & 63 & 71.6 \\
\hline
\end{tabular}




\section{Total}

Years of

Service

$$
1-5 \text { years }
$$

6-10 years

$11-15$ years

16-20 years

21-25 years

26-30 years

31-35 years

Total

$\begin{array}{ll}\text { Religion } & \text { Islam } \\ & \text { Christianity } \\ \text { Buddhist } \\ \text { Hindu } \\ \text { Other } \\ \text { Total }\end{array}$

76

$\begin{array}{lllllll}100.0 & 8 & 100.0 & 4 & 100.0 & 88 & 100.0\end{array}$

\section{6}

25

11

3

4

4

$\begin{array}{rrrrrrr}34.2 & 5 & 62.5 & 3 & 75.0 & 34 & 38.6 \\ 32.9 & 3 & 37.5 & 1 & 25.0 & 29 & 33.0 \\ 14.5 & 0 & .0 & 0 & .0 & 11 & 12.5 \\ 3.9 & 0 & .0 & 0 & .0 & 3 & 3.4 \\ 5.3 & 0 & .0 & 0 & .0 & 4 & 4.5 \\ 5.3 & 0 & .0 & 0 & .0 & 4 & 4.5 \\ 3.9 & 0 & .0 & 0 & .0 & 3 & 3.4\end{array}$

$\begin{array}{llllllll}100.0 & 8 & 100.0 & 4 & 100.0 & 88 & 100.0\end{array}$

\begin{tabular}{rrrrrrrr}
76 & 100.0 & 0 & .0 & 0 & .0 & 76 & 86.4 \\
0 & .0 & 1 & 12.5 & 0 & .0 & 1 & 1.1 \\
0 & .0 & 7 & 87.5 & 0 & .0 & 7 & 8.0 \\
0 & .0 & 0 & .0 & 4 & 100.0 & 4 & 4.5 \\
0 & .0 & 0 & .0 & 0 & .0 & 0 & .0 \\
$\mathbf{7 6}$ & $\mathbf{1 0 0 . 0}$ & $\mathbf{8}$ & $\mathbf{1 0 0 . 0}$ & $\mathbf{4}$ & $\mathbf{1 0 0 . 0}$ & $\mathbf{8 8}$ & $\mathbf{1 0 0 . 0}$ \\
\hline $\mathbf{n}$
\end{tabular}

\subsection{Interview and E-interview Respondents}

From the 27 targeted respondents, 21 respondents completed the interview phase of this study, 14 were interviewed in person, and seven were e-interviewed. Most interview respondents were Malays, with four Chinese and one Indian respondent. Other potential Indian and Chinese respondents withdrew due to work and study commitments. As such, obtaining the participation of respondents from these ethnic groups proved to be challenging due to the small number.

\subsection{Uncertainty Avoidance Paradigm}

It was argued that a society with HUA preferred strict codes of belief and may be intolerant of nonconformist behaviours and ideas. Hence, HUA societies worried about the future and preferred to work with clear rules and regulations, with the belief that deviations were dangerous, and formality should be valued. On the contrary, LUA cultures were more open to new ideas and changes with less uncertainty about the future, avoided complex rules and formalities, and easily accepted new ideas (Hofstede, 2012; Hofstede and Minkov, 2010).

This section analysed data on the respondents' expectations towards rules, changes, and creativity linked to uncertainty avoidance and investigated the differences between the respondents' behaviour in HUA or LUA and the effect of these differences in the respondents' communication.

\subsection{Expectations towards Rules, Changes, and Creativity 4.4.1 Expectations towards rules}

Table 2 highlights that $92 \%$ of the respondents felt uneasy with the absence of clear rules at the workplace. The findings indicated that $93.4 \%$ of the Malays answered 'Yes' to this question, $75 \%$ of Chinese respondents chose the same answer, followed by $100 \%$ of the Indian respondents selecting 
'Yes'. However, $6.6 \%$ of the Malay respondents and $25 \%$ of the Chinese respondents were tolerant of vague rules. The findings suggested that the three ethnic groups were inclined to demonstrate HUA values.

Table 2. Rules at the workplace

\begin{tabular}{|c|c|c|c|c|c|c|c|c|c|c|}
\hline & & & & & \multicolumn{2}{|c|}{ Chinese } & \multicolumn{2}{|c|}{ Indian } & \multicolumn{2}{|c|}{ Total } \\
\hline & & & $\begin{array}{l}\text { Frequency } \\
\text { (n) }\end{array}$ & $\begin{array}{l}\text { Percentage } \\
(\%)\end{array}$ & (n) & $(\%)$ & (n) & $(\%)$ & (n) & $(\%)$ \\
\hline \multirow[t]{3}{*}{ Cul.19 } & I feel uneasy in & No & 5 & $6.6 \%$ & 2 & $25.0 \%$ & 0 & $.0 \%$ & 7 & $8.0 \%$ \\
\hline & situations with no & Yes & 71 & $93.4 \%$ & 6 & $75.0 \%$ & 4 & $100.0 \%$ & 81 & $92.0 \%$ \\
\hline & $\begin{array}{l}\text { clear rules at my } \\
\text { workplace. }\end{array}$ & Total & 76 & $100.0 \%$ & 8 & $100.0 \%$ & 4 & $100.0 \%$ & 88 & $100.0 \%$ \\
\hline
\end{tabular}

People in a HUA society tended to follow rules faithfully. For example, the interview data demonstrated that Malay respondents differed with regards to HUA or LUA. Respondents at the upper professional levels observed that rules were important and considered the obligation of rules to be vital, as the rule makers and were charged with implementing these rules.

...every rule, big or small at the workplace, is a rule that I should follow because this had been decided by the management. Plus I'm involved in outlining the rules. (Yusuf, male, Malay, upper-level professional)

Malay respondents involved in outlining the rules regarded these regulations to be important at the workplace. As such, the rules were followed in line with work etiquette, culture, and religion. The Malay respondents also preferred to obey rules to avoid controversy and perceived that disobeying the rules would result in deficiency and delinquency, thus negatively affecting the institution's production. This finding identified that religion provided a basic principle for actions too. Therefore, the Malay respondents may possess HUA, as religion was an important criterion for HUA and reflected the value of the absolute Truth.

... I'll obey the rules not because I want to be accepted, but I prefer to observe the rules, it is my personality. I will not disobey any rules as long as the rule is not against etiquette, culture and my religion. (Khadijah, female, Malay, middle-level academic)

I don't want to create controversy...so I just obey. (Amina, female, Malay, middle-level academic)

Furthermore, Malay respondents at the administrative support level preferred to observe rules and regulations. In some circumstances, this comprised part of the nature of the respondents' job. As Daud (male, Malay, support level administration), explained, his workplace required rules to be followed in conveying a good impression of his department. Therefore, Daud's job scope in enforcing rules and regulations required him to respect the rules and regulations.

To Fatima (female, Malay, support level administration), obeying rules were important as her job involved laboratory work that required pre and post procedures in the usage of laboratories. As such, all the laboratories at Fatima's workplace complied with the same rules and enabled her to do execute the 
task. Sarah (female, Malay, support level administration) preferred to obey clear rules as stated in the circular at her workplace and believed that non-compliance of these rules would create issues.

All the Malay respondents, regardless of the organisational level, observed that obeying rules reflected HUA values and was supported by religion. Thus, complying with rules did not imply blind following, but this compliance concurred with the basic tenets of faith as supported by Lrong (2001), thus signifying that the Malays were fatalistic and took the will of God as a justification for events. Lrong (2001) also reported that the government's rules regarding the New Economic Policy to lessen and evade ambiguities was a political outcome of the Malay psyche, suggesting that the Malays needed assurance (Lrong, 2001).

One Chinese respondent, Lei Hua (female, Chinese, upper level academic), revealed discomfort in having too many rules at the workplace and was uneasy about having extensive rules and regulations which may hinder creativity. Nevertheless, she also felt it to be inappropriate if an employee violated the basic institutional rules. Although Lei Hua did not strictly adhere to the rules herself, she preferred that the specified institutional rules not be disobeyed.

I believe too many rules will restrict you. Yet you cannot be free all time, you need to be under control sometime. But not too much because it will restrict your job... (Lei Hua, female, Chinese, upper-level academic)

She also considered it important not to deviate from the stated rules and indicated leniency in observing the rules related to LUA. Also, complying with extensive rules was distressful, indicating that on an individual basis, the Chinese too could value LUA. In other words, Lei Hua's position in this institution influenced her perception, which suggested that an employee's position could also influence actions on observing rules.

Nevertheless, the Chinese respondents seemed to vary in attitudes towards observing rules. Liang (male, Chinese, middle-level academic) believed that rule deviations resulted in warnings and subsequent prosecutions by the management. However, Lei Hua (female, Chinese, upper-level academic) was uncomfortable with the tedious rules. The single Indian respondent, Aditya (male, Indian, middle-level academic), perceived that rules should be obeyed as a sign of professionalism and regarded rules as professional guidelines that led to an excellent career.

In summary, the survey respondents demonstrated HUA, regardless of ethnicity, which was generally consistent with the survey findings. All the Malay, Chinese and Indian respondents in the interviews perceived that rules should be observed, thus indicating HUA values. As such, this outcome refuted the generalisation by Hofstede (1991), which indicated that Malays generally reflected LUA. On the contrary, HUA was observed in some conditions.

Nevertheless, Hofstede's finding as a generalisation failed to explain the differences within individual ethnic cultures. This indicated that not many differences were detected with regards to rules observation concerning these three ethnic groups, as there was a consensual agreement in observing important rules. This finding was verified by several studies explaining that Malays, Chinese, and Indians shared common HUA values in observing rules and regulations (Dahlia, 2008; Hamzah, 1991; Lrong, 2001).

\subsubsection{Changes and adaptation}

Table 3 indicates that $80.7 \%$ of the respondents were conducive to change. Ethnically, $82.9 \%$ of Malay, $62.5 \%$ of Chinese, and $75 \%$ of Indian respondents indicated discomfort with changes or reorganisations. Thus, the findings appeared to demonstrate signs of LUA in respondents' reactions to 
workplace changes, where a sense of comfort with ambiguity and uncertainty was observed. The results signified that the respondents indicated LUA, whereby $86.8 \%$ of Malays, $75 \%$ of Chinese, and $75 \%$ of Indians were confident in accepting changes which could result in direct effects at the workplace. Only a small number of Malay, Chinese, and Indian respondents felt threatened by change. The three ethnic groups signified LUA, which indicated that transformation was valued and sufficient competency existed in facing professional challenges, in line with Hofstede's (2001) generalisation on Malaysia as a LUA society.

Table 3 demonstrates that $81.8 \%$ of the respondents were nonchalant about being transferred to other departments, thus signifying LUA. It was reported that the Malay respondents $(84.2 \%)$ could adapt to departmental changes. Similarly, $62.5 \%$ of Chinese and $75 \%$ of Indian respondents (refer Table 3) demonstrated acceptance for transformational processes, consequently reflecting LUA through an openminded society with less concern on ambiguity and uncertainty, and more readiness for change and risktaking (Hofstede and Minkov, 2010). Also, 95.5\% of the respondents (refer Table 3) were willing to face challenges and felt more adventurous at the workplace. Categorically, $94.7 \%$ of Malay, $100 \%$ of Chinese, and $100 \%$ of Indian respondents preferred challenges compared to routine tasks. This indicated that, regardless of ethnicity, all the groups valued LUA and felt comfortable with ambiguity and uncertainty. However, a small number of respondents were threatened by change.

The interview findings supported and expanded the survey data on uncertainty avoidance. As such, HUA signified that change (or transformation) in the form of novel concepts or ideas posed threats and anxiety about the future, compared to LUA which highlighted a willingness to accommodate new ideas and change with less worry on uncertainty and the future. Malay respondents generally accepted changes or departmental transfers for the sake of the institution. Hence, adaptation to a new place and preparedness in facing new situations was crucial.

Table 3. Changes and challenges at the workplace

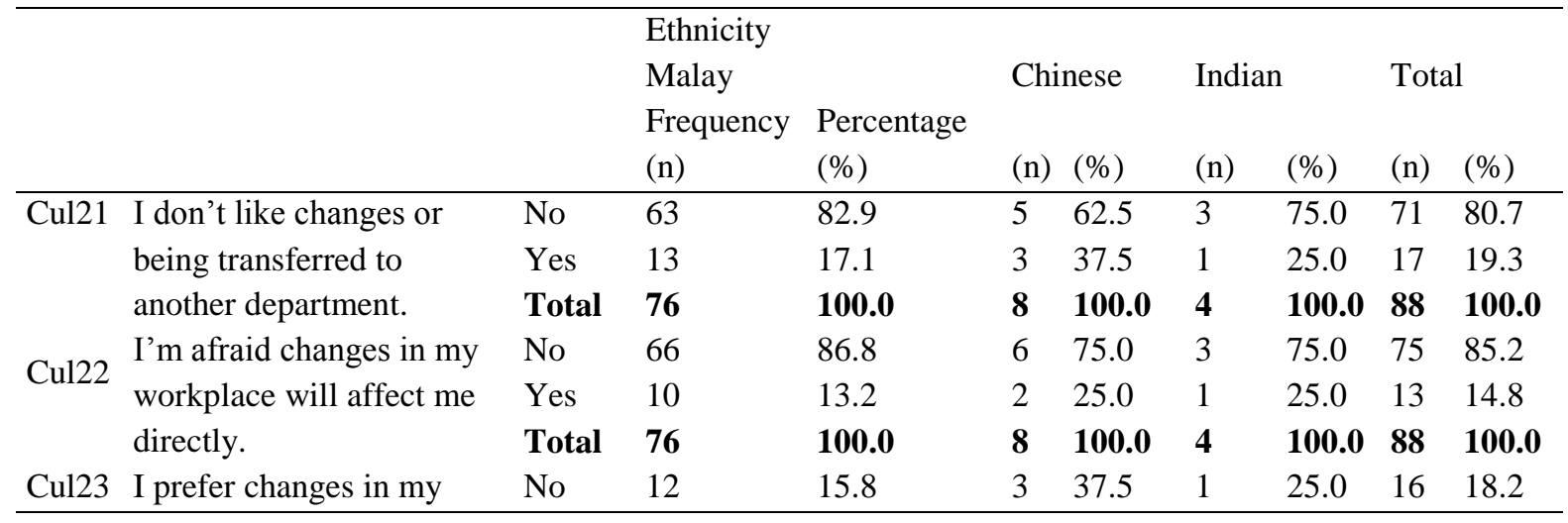




\begin{tabular}{|c|c|c|c|c|c|c|c|c|c|c|}
\hline & workplace, and I'm not & Yes & 64 & 84.2 & 5 & 62.5 & 3 & 75.0 & 72 & 81.8 \\
\hline & $\begin{array}{l}\text { worried about being } \\
\text { transferred to another } \\
\text { department. }\end{array}$ & Total & 76 & 100.0 & 8 & 100.0 & 4 & 100.0 & 88 & 100.0 \\
\hline \multirow[t]{3}{*}{$\mathrm{Cul} 24$} & I prefer challenges in my & No & 4 & 5.3 & 0 & .0 & 0 & .0 & 4 & 4.5 \\
\hline & work rather than doing & Yes & 72 & 94.7 & 8 & 100.0 & 4 & 100.0 & 84 & 95.5 \\
\hline & routine tasks. & Total & 76 & 100.0 & 8 & 100.0 & 4 & 100.0 & 88 & 100.0 \\
\hline
\end{tabular}

The Malay respondents, regardless of the managerial level, acknowledged that as government servants, departmental transfers may not be personally favourable, but the preparedness to face workplace challenges was evident. Notwithstanding, the university's policy dictated that upon completing five years in a specific department, the employee should be relocated to another department. As such, Malay respondents at the upper professional level experienced reshuffling and restructuring when employed at previous companies and institutions before settling in UMT. The changes due to these transfers were adapted to and viewed positively. Based on prior experience, the employees believed that change offered an approach to the problems encountered at the workplace. In this vein, attitudes towards change were influenced as much by the Malay policy as cultural orientation.

The Malay respondents observed change positively with a readiness to face professional challenges. Also, change was viewed as the characteristic of a dynamic environment, enabled new experiences, enhanced productivity, creativity, efficiency, and added value to the institution's advancement. In this regard, the transformation was a positive mechanism in producing more efficiency, meticulousness, and systematisation at work.

Basically, when we were moved to some other departments, normally we ask for these ourselves, which we really love to do. It will be no problem to me. (Khadijah, Malay, middle- level academic)

The transformation was also considered essential, as it was believed that change increased with potential learning experiences and knowledge. Respondents were also able to appreciate diverse cultures and societies in the workplace. For example, Yahya (male, Malay, middle-level administration) mentioned that during his years at Hospital Universiti Kebangsaan Malaysia, departmental transfers were a professional norm. With the occurrence of the same experience in UMT, there was a preparedness to face the challenges at work with no qualms in serving the institution under this policy.

Nevertheless, a small number of Malay respondents objected to change, as it was regarded to be troublesome or a burden and caused distress in the event of a departmental transfer. Mohammad (male, Malay, middle-level academic) preferred transformation to occur gradually with appropriate planning or strategies to embrace the change.

If the changes that had been made are something put upon me, I'll reject it. Let say, a punch card issue, that it should be punched twice, is an issue I feel really uncomfortable with. I think it will not fit with my flexi hours of working. (Amina, female, Malay, middle-level academic)

On the other hand, Chinese and Indian respondents shared a common value for uncertainty avoidance in transformation and seemed ready to experience different situations. As such, the perspective towards transformation was positive and exuded confidence, as there was no fear in facing change. It was also acknowledged that routine tasks could be dull and tedious. Additionally, Chinese respondents considered 
that in a university, the transformation was useful for advancement and improvement of the staff. Besides, as university staff, there should be an adequate level of preparedness in competing within the higher education context and change could improve work performance, generate a new environment at work, and produce a healthy workforce. In other words, restructuring and transformation helped in avoiding any favouritism that may occur in the department.

Changing the management and a new work environment could enhance our performance and promote healthy work etiquette. (Liang, male, Chinese, middle-level academic)

However, a Chinese respondent did view change negatively, as there was a fear that change would directly affect her normal practice.

I guess, like everyone, any transformation or changes will frighten me. (Jessica, female, Chinese, middle-level academic)

With regards to Jessica's position, it was noteworthy to observe that change was viewed unfavourably. As a lecturer, the reaction towards change was negative despite being well-educated.

Overall, all three ethnic groups indicated LUA, with only a small number indicating HUA. The Malay attitude towards change was linked to age and seniority at the management level. The findings also indicated a slight difference regarding uncertainty avoidance on the transformation experienced by the three ethnic groups in this study and were supported by several studies (Dahlia, 2008; Hamzah, 1991; Lrong, 2001), which noted that these ethnic groups perceived change positively, thus opposing the findings suggested by Hofstede (1991) which generalised Malays to experience HUA. The Indian respondent highlighted the values of LUA and believed that any challenge could be confronted. This finding was in line with Dahlia (2008) and opposed Hofstede's (1991) findings which reported Malaysian Indians to have HUA values.

However, it was made aware in this study that one Indian respondent was not representative of the general Malaysian Indian population. Nonetheless, the respondent did contribute to the study and highlighted that Malaysian Indians also underwent a shift of paradigm in uncertainty avoidance. This finding was also consistent with the Uncertainty Avoidance Index, which indicated that Malaysia was essentially LUA compared to Far East Asian countries, such as Hong Kong or Japan (Oluwabusuyi, 2011). However, a small number of Malay and Chinese middle-level academics did portray HUA criteria due to personal experiences and feelings of contentment with the current department or position. As Lrong (2001) remarked, Malays believed the future to be too intricate, ambiguous, unpredictable, and hostile for efficient planning.

\subsubsection{Creativity}

Table 4 signifies that $83 \%$ of the respondents believed that creativity could be expressed freely in the workplace. The survey respondents, regardless of ethnicity, exhibited signs of LUA, where creativity and innovation were appreciated, and accepted variety and experimentation (Hofstede and Minkov, 2010; Sánchez-Franco et al., 2009). This finding also contradicted Hofstede's generalisation (2001, 2012) but coincided with Ayoun and Moreo (2008), who described Malaysia as a country with LUA due to the evolving business environment 
Table 4. Creativity at work

\begin{tabular}{|c|c|c|c|c|c|c|c|c|c|c|}
\hline & & & \multicolumn{8}{|l|}{ Ethnicity } \\
\hline & & & \multicolumn{2}{|l|}{ Malay } & \multicolumn{2}{|c|}{ Chinese } & \multicolumn{2}{|c|}{ Indian } & \multicolumn{2}{|c|}{ Total } \\
\hline & & & (n) & $(\%)$ & (n) & $(\%)$ & (n) & $(\%)$ & (n) & $(\%)$ \\
\hline \multirow[t]{3}{*}{ Cul25 } & \multirow{3}{*}{$\begin{array}{l}\text { I can express my } \\
\text { creativity freely in my } \\
\text { workplace. }\end{array}$} & No & 15 & 19.7 & 0 & .0 & 0 & .0 & 15 & 17.0 \\
\hline & & Yes & 61 & 80.3 & 8 & 100.0 & 4 & 100.0 & 73 & 83.0 \\
\hline & & Total & 76 & 100.0 & 8 & 100.0 & 4 & 100.0 & 88 & 100.0 \\
\hline
\end{tabular}

The interview findings supported the survey data with creativity among the LUA characteristics that acknowledged new ideas, compared to HUA, which is less tolerant of new concepts. In general, the Malay respondents in this study viewed creativity positively, which was believed to provide excellent service to the campus community. For example, the Malay respondents from each level perceived creativity to be necessary at work in solving everyday problems with minimal expenditure. In some departments, the respondents were encouraged to participate in Kumpulan Inovasi dan Kreativiti (KIK or Innovation and Creativity Group).

The upper levels channelled creativity through ideas, such as the formation of an 'Idea Bank'. The value of creativity also depended on the position and seniority of the employee. Awang (male, Malay, upper-level professional), for example, supported and encouraged subordinates to generate creativity and inventiveness at work. At this stage of his career, Awang was expected to provide the ideas and expected subordinates to implement these ideas. He also explained that versatility and creativity at work without complete dependence on upper-level instructions was appreciated.

At the workplace, the implementation and adaptation of work ethics practised by the Japanese to the local environment were attempted. This work ethics, referred to as $2 \mathrm{~S}$ [sapu (sweep) and susun (systematise)], concerned a tidy and organised office environment and reflected that the upper levels valued LUA in terms of innovation and experimentation. This is since being at the upper level allowed for the implementation of creative ideas in the system to aid organisational performance by providing excellent service. A high value was also placed on creativity by inspiring the subordinates.

Another example was shared by Yahya (male, Malay, middle-level administration), who explained that in his unit, there was a need to deal with very important people (VIPs), the subsequent protocols, and last-minute changes. In this regard, speed and creativity with minimal errors were of utmost importance in ensuring that all the VIPs were satisfied with the service. Malay academics at the middle level felt free to express creativity in the form of writing and publishing papers, conducting research, and performing teaching and learning tasks.

As such, the management did not impose restrictions in presenting educational ideas, including the preparation of exam questions, and marking papers where creativity was allowed within the compliance of the basic rules. Therefore, the Malay support level staff were allowed to be creative at work, such as in preparing the lab schedules, taking meeting minutes and organising information, and helping to plan office interiors.

If there are any changes in office interiors, we are allowed to organise them according to our creativity without many limitations from the upper levels. Provided it is appropriate for the office ambience and does not go beyond the regulations. (Sarah, female, Malay, support level administration)

However, one Malay respondent viewed creativity negatively. Amina (female, Malay, middle level academic) decided to do her PhD in her field of interest but gained no support from her Dean. However, 
after providing evidence on her interest, she was allowed to research the chosen area for her $\mathrm{PhD}$. However, she had to fight for what she wanted, which led to the viewing of creativity as underappreciated at the workplace.

On another note, the Chinese and Indian respondents generally perceived creativity positively. Creativity was appreciated if this could improve productivity and reduce the organisation's costs. Therefore, employees in the academic fields were allowed to be creative in learning, teaching, researching, and initiating new ideas at the workplace as indicated by Lei Hua (female, Chinese, upperlevel academic), Steven (male, Chinese, middle-level academic), Jessica (female, Chinese, middle- level academic), and Aditya (male, Indian, middle-level academic).

These respondents could utilise UMT's resources, ways, and methods in researching with no restrictions from the upper management on the presentation of the research methods and results. As academics, it was believed that the teaching and learning process should be consistently improvised without reliance on conventional learning styles. For example, humour was allowed during the educational sessions as a form of creativity without altering the syllabus.

I guess creativity should relate to productivity and reduce costs because this will increase efficiency. (Liang, male, Chinese, middle-level administration)

The findings indicated that Malay respondents valued LUA with regards to creativity. However, for the Malay respondents at the upper level, LUA was also influenced by aspects concerning positions and seniority. Surprisingly, one Malay respondent from the middle level had a negative experience concerning creativity and concluded that creativity was undervalued at work.

This was the only exception, considering that the respondent belonged to the middle-level management, which explained the respondent's status in an organisation where the hierarchy was important and suggestions were considered at the discretion of the organisation (Ayoun and Moreo, 2008, Bakar et al., 2007, Dahlia, 2008, Kim and McLean, 2014). Interestingly, all the Malays in the support level indicated that creativity was not encouraged or supported by the management.

The majority of the Chinese respondents indicated LUA in appreciating the creativity and new ideas expressed by colleagues or employers. There were minor differences in the uncertainty avoidance exhibited by the Indian respondent compared to the other two ethnic groups. The overall findings indicated that all the ethnic groups in this study signified LUA by appreciating new ideas, creativity, and innovation.

There were fewer differences among the three ethnic groups as LUA was indicated in creativity and inventions, in line with Hofstede's (2001) generalisation that Malaysia held a relaxed attitude towards ambiguity and appreciated innovative creativity as a LUA society. However, Hofstede's cultural dimensions should not be considered static, as evidence indicated that people affiliated with these dimensions, thus confirming Hofstede's criticisms (McSweeney, 2001). 


\section{Conclussion}

The study contributed to the area of intercultural communication in the Malaysian context and highlighted the need for UMT's personnel to recognise the importance of understanding colleagues' cultural backgrounds and how this understanding contributed to effective workplace communication. The results also suggested the need for UMT to consider enhancing the organizational culture by raising the profile of and valuing multiculturalism.

\section{Acknowledgments}

Thank you to Universiti Malaysia Terengganu for their kind co-operation and encouragement which help me in completion of this project.

\section{References}

Asma, A., \& Lim, L. (2001). Cultural Dimensions of Anglos, Australians, and Malaysians. Japan Malaysian Management Review, 36(2), 1-17.

Ayoun, B. M., \& Moreo, P. J. (2008). The influence of the cultural dimension of uncertainty avoidance on business strategy development: a cross-national study of hotel managers. International Journal of Hospitality Management, 27(1), 65-75.

Bakar, H. A., Mohamad, B., \& Mustafa, C. S. (2007). Superior-Subordinate Communication Dimensions and Working Relationship: Gender Preferences in a Malaysian Organization. Journal of Intercultural Communication Research, 36(1), 51-69.

Brubaker, R. (2002). Ethnicity without groups. European Journal of Sociology, 43(2), 163-189.

Dahlia, Z. (2008). Cultural dimensions among Malaysian employees. International journal of economics and management, 2(2), 409-426.

Fontaine, R., \& Richardson, S. (2005). Cultural Values in Malaysia: Chinese, Malays and Indians Compared. Cross Cultural Management: An International Journal, 12(4), 63-77.

Fuller, T. (2006, 15 November). Malaysia's leader warns of religious and ethnic tensions. The New York Times. Retrieved from http://www.nytimes.com/2006/11/15/world/asia/15iht-malay.3544364.html?_r=1

Hall, E. T. (1959). The silent language. Garden City, N.Y: Doubleday.

Hall, E. T. (1966). The hidden dimension. Garden City, N.Y: Anchor Books.

Hamid, A. F. A. (2010). Islamic Education in Malaysia: The Pre-Independence Era. RSIS Monograph, 18, 13-24.

Hamzah, S. (1991). Managing in Multicultural society - the Malaysian experience. Malaysian Management Review, 1, 61-69.

Hofstede, G. (1991). Management in a multicultural society. Malaysian Management Review, 26(1), 3-12.

Hofstede, G., Hofstede, G. J., \& Minkov, M. (2010). Cultures and Organizations: Software of the Mind (3rd ed.). 
New York: McGraw-Hill USA.

Hofstede, G., \& Bond, M. H. (1984). Hofstede's Culture Dimensions an Independent Validation Using Rokeach's Value Survey. Journal of cross-cultural psychology, 15(4), 417-433.

Hofstede, G., \& Bond, M. H. (1988). The Confucius connection: From cultural roots to economic growth. Organizational dynamics, 16(4), 5-21.

Hofstede, G., \& Minkov, M. (2010). Long-versus short-term orientation: new perspectives. Asia Pacific business review, 16(4), 493-504.

Hofstede, G. (2001). Malaysia Cultural Dimensions Retrieved 16 February, 2010, from http://geerthofstede.com/malaysia.html

Hofstede, G. (2012). National culture dimension. Retrieved 18 August, 2012, from http://geerthofstede.com/dimensions.html

Jackson, T. (2020). The legacy of Geert Hofstede. International Journal of Cross-Cultural Management, 20(4), 3-6.

Kim, S. \& McLean, G. N., (2014). The impact of national culture on informal learning in the workplace. Adult Education Quarterly, 64(1), 39-59.

Knapp, M. L. \& Hall, J. A. (2006). Nonverbal communication in human interaction (6th ed.). Array Belmont, CA: Wadsworth/Thomson Learning.

Lrong, L. (2001). Work-related values of Malays and Chinese Malaysians. International Journal of Cross-Cultural Management, 1(2), 209-226.

Majid, L. A., Hussin, H., Ismail, A. M., Stapa, Z., Nazri, M. A., Sabri, M., Othman, F. M., \& Shah, A. F. (2012). The Contribution of Islamic Education in Strengthening Malay Identity. Journal of Applied Sciences Research, 8(8), 4322-4327.

Mardman, H. (2011). Egypt's influence on the education of Thai Muslims from the Nasser Era to the Present. In K. B. Ahmad \& P. Jory (Eds.), Islamic Studies and Islamic Education in Contemporary Southeast Asia (pp. 37). Kuala Lumpur: Yayasan Ilmuwan.

Mydans, S. (2010, 20 January). 8 Arrested in Firebombing of Malaysian Churches. The New York Times. Retrieved from http://www.nytimes.com/2010/01/21/world/asia/21malay.html Naji, I.M.H., \& David, M.K. (2003).

Oluwabusuyi, I. (2011). Are Malaysian managers more rational than United States of managers?, Interdisciplinary Journal of Research in Business, 1(1), 13-20.

Othman, N., \& Mohamad, K. A. (2011). Eclectic Model in the Malaysian Education System. International Education Studies, 4(4), 111-122.

Pandian, A. (2008). Multiculturalism Higher education: A case study of Middle Eastern students' perceptions and experiences in a Malaysian university. International Journal of Asia Pacific Studies, 4(1), 33- 59. 
Panocova, R. (2020). Theories of Intercultural Communication. Retrieved 18 August 2020, from https://unibook.upjs.sk/img/cms/2020/ff/theories-of-intercultural-communication.pdf\#page $=26$

Sánchez-Franco, M. J., Martínez-López, F. J., \& Martín-Velicia, F. A. (2009). Exploring the impact of individualism and uncertainty avoidance in Web-based electronic learning: An empirical analysis in European higher education. Computers \& Education, 52(3), 588- 598.

Shamsul, A. B, \& Aziz, A. (2011). Colonial Knowledge and The Reshaping Of Islam, The Muslim And Islamic Education In Malaysia. In K. B. Ahmad \& P. Jory (Eds.), Islamic Studies and Islamic Education In Contemporary Southeast Asia (Pp. 113). Kuala Lumpur: Yayasan Ilmuwan.

Sitaram, K.S. (1980). Intercultural Communication: The What and Why, International \& Intercultural Communication Annual, 30, 90-96.

Terengganu history. (2013, 7 March 2013). Retrieved 10 March 2013, from http://www.terengganu.gov.my/ Terengganu Malay language. (2012).

McSweeney, B. (2001). Hofstede's Model of National Cultural Differences and Their Consequences: A triumph of faith - A failure of analysis" (abridged). European Business Forum, (Dr. Geert Hofstede ${ }^{\mathrm{TM}}$ Cultural Dimensions). http://geert-hofstede.internationalbusiness-center.com/mcsweeney.shtml 